\title{
Induction of reproductive diapause in Hippodamia convergens (Coleoptera: Coccinellidae) hinges on prey quality and availability
}

\author{
J.P. MICHAUD and JAWWAD A. QURESHI
}

Department of Entomology, Kansas State University, Agricultural Research Center - Hays, $1232240^{\text {th }}$ Ave, Hays, KS 67601, USA; e-mail: jpmi@ksu.edu

Key words. Reproductive diapause, Coccinellidae, Hippodamia convergens, Schizaphis graminum, Ephestia kuehniella, Helianthus annuus

\begin{abstract}
In the High Plains of western Kansas, USA, the convergent lady beetle Hippodamia convergens Guérin completes a spring generation feeding on cereal aphids in winter wheat before leaving fields in large numbers around the time of harvest. In late May, large aggregations of coccinellids form on wild sunflowers, Helianthus annuus, and certain other weeds, that appear to serve as important sources of water absorption for the beetles, and other beneficial insects, during the dry prairie summer. Adult beetles were collected from sunflower plants and held in four treatments: (1) access to water only, (2) access to sunflower stalks only, (3) eggs of Ephestia kuehniella provided ad libitum + water and, (4) greenbug, Schizaphis graminum Rondani provided ad libitum. Most females fed greenbug matured eggs in less than a week and only a few entered reproductive diapause. In contrast, more than half of the females fed Ephestia eggs, an inferior diet, entered reproductive diapause, and those that matured eggs required an average of almost three weeks to do so. Time to $50 \%$ mortality was 7 days for beetles receiving only water, and 12 days for those receiving only sunflower stalks, whereupon all survivors were fed greenbug. Even after feeding on greenbugs for a month, less than half of the surviving females in these two treatments produced eggs. We conclude that reproductive diapause is an important adaptation for improving $H$. convergens survival during summer when aphids are scarce, although females will forgo diapause if they have continuous access to high quality prey.
\end{abstract}

\section{INTRODUCTION}

Winter wheat, Triticum aestivum L., is the dominant agricultural crop in the High Plains of the central United States. In early spring, fall-planted winter wheat and coolseason native grasses break winter dormancy and enter a period of rapid growth. Colonies of cereal aphids, e.g., Schizaphis graminum Rondani, Diuraphis noxia (Mordvilko), and Rhopalosiphum padi (L.), can develop rapidly on these grasses during favorable spring weather and usually provide an abundant food resource for the various coccinellid species that emerge from hibernation at this time. Species such as Hippodamia convergens Guérin, Coleomegilla maculata DeGeer and Coccinella septempunctata L. typically complete a single spring generation feeding on these cereal aphids and then emigrate en masse from maturing wheat fields as they dry down prior to harvest, usually in late May. These emigrant adults typically face a hot, dry prairie summer with very low aphid populations. Adults of many Coleoptera have evolved an aestival reproductive diapause to enhance survival during such adverse summer conditions (Masaki, 1980). Coccinellid species capable of avoiding reproduction during this period can benefit from reduced energy demands when prey are scarce, but are still obliged to find adequate supplies of food and water to sustain them until conditions favor the resurgence of aphid populations sufficient to support both adult reproduction and larval development.

The annual sunflower, Helianthus annuus L., is a plant indigenous to North America that grows wild throughout the High Plains and is also widely cultivated for its seed and oil in the same region. The insect fauna associated with sunflower is extremely diverse and includes a wide array of predaceous arthropods that are associated with the plants at various stages of their development (Royer \& Walgenbach, 1991). These include large, multispecies aggregations of adult coccinellid beetles that frequently form on young sunflower plants following their emigration from wheat fields in late May and early June (Fig. 1). The beetles can be observed mating, but no aphids or other potential prey are normally present on the sun-

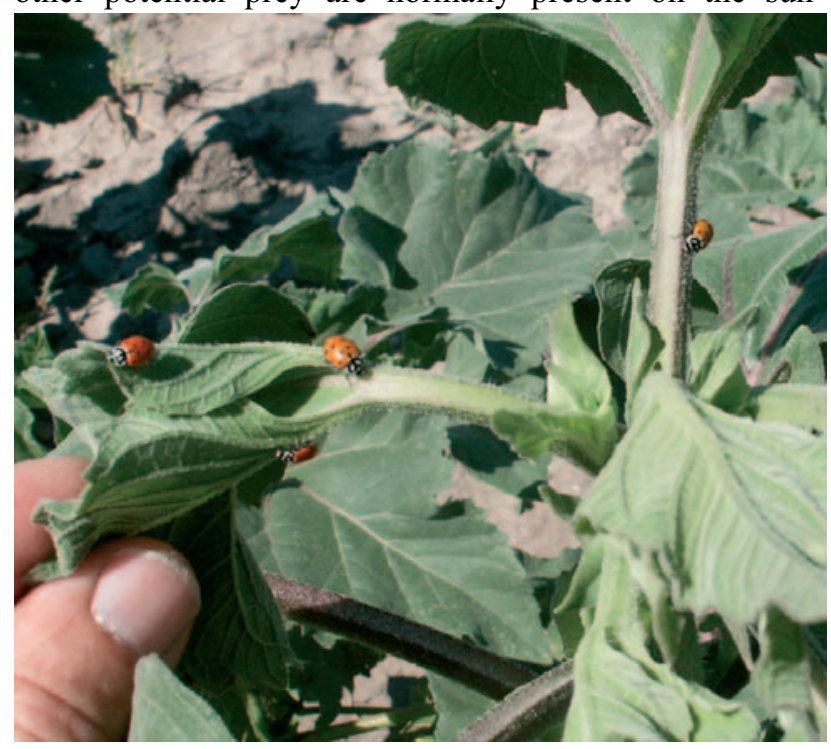

Fig 1. Adult Hippodamia convergens aggregating on wild sunflower plants in late May. 

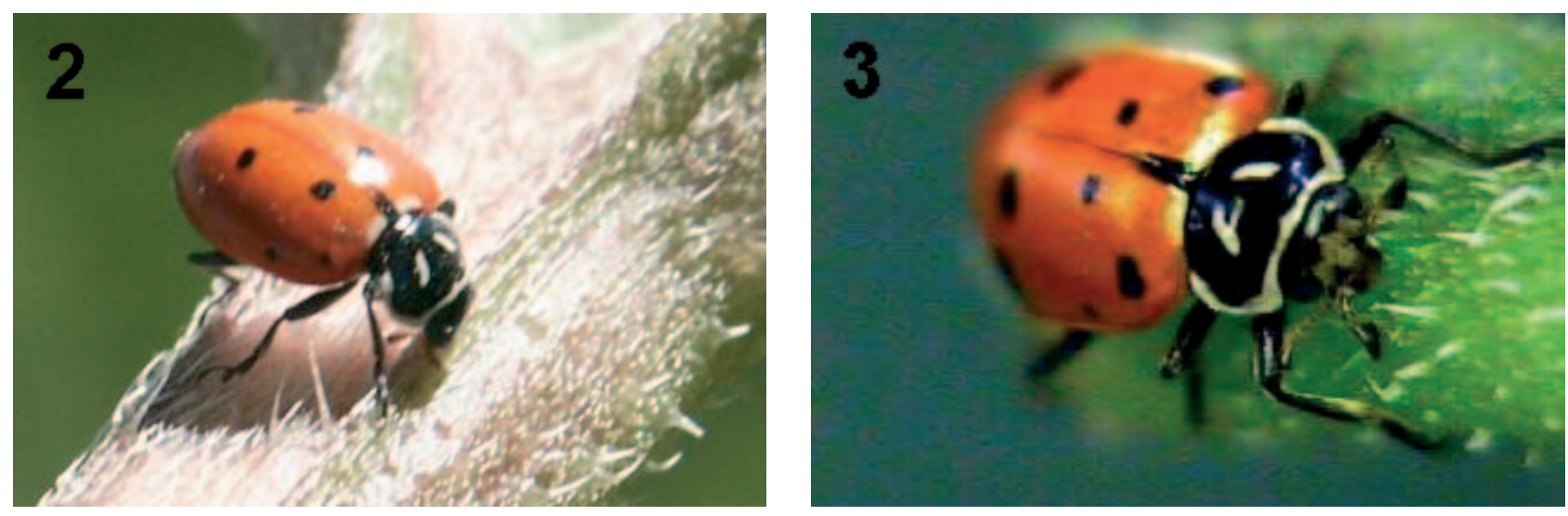

Figs 2-3. Closeups of adult Hippodamia convergens drinkings sap from a sunflower plant.

flowers at this time, nor are any coccinellid eggs or larvae in evidence. It is difficult to ascertain what sort of food or prey might have been consumed by these beetles prior to their arrival at the plants, but the guts of most dissected individuals appear to be empty. Rather, the adults appear to embed their mouthparts in the stems and leaves and drink the sunflower sap (Figs 2,3), although no permanent, recognizable damage to the plant results from this behavior. The High Plains can be an exceedingly arid region during summer months and even dew can become a scant resource for arthropods seeking water absorption. Thus sunflowers, as well as certain other weeds with succulent stalks and foliage, essentially serve as drinking wells for a wide array of thirsty arthropods, bringing up moisture from deep in the soil and rendering it available for any insect capable of puncturing the plant's epidermis.

Adult coccinellids experiencing dehydration are known to drink readily when free water is provided (Hagen, 1962; Michaud \& Grant, 2005) and sometimes form large aggregations on beaches or the shores of lakes (Turnock \& Turnock, 1979). A number of reports of adult coccinellids feeding on succulent plant parts have been interpreted as a form of drinking behavior (Hodek \& Honěk, 1996) that may function in the rehydration of beetles emerging from hibernation. Observations of apparent plant feeding by C. septempunctata led Brassler (1930) to question whether this species was actually a specialized aphid feeder. Similarly, the invasive Harmonia axyridis Pallas has caused problems in grape, pome, and stone fruit production in the USA because of its propensity to damage ripening fruit (Koch, 2003; Cloyd, 2004), although to what extent the behavior is driven by sugar versus water content of the juice remains undetermined.

Having observed a mass exodus of adult coccinellids from maturing wheat fields for several seasons in succession, followed by their subsequent aggregation on sunflowers, we decided to investigate the value of sunflowers as a resource for adult beetles in the absence of prey. We selected $H$. convergens for study because it is consistently the most abundant aphidophagous coccinellid in our region. We were aware also that adults of this species tended to enter a reproductive diapause when reared under laboratory conditions on certain diets. Thus, our objectives were to determine (1) the reproductive status of female beetles aggregating on sunflower plants, (2) the value of sunflower sap in enhancing beetle survival in the absence of food, and (3) whether reproductive diapause in female beetles is induced by low food quality and/or availability.

\section{MATERIAL AND METHODS}

A total of 344 adult $H$. convergens were collected from wild sunflower plants in Hays, Kansas on 25 May, 2004 (= day "0" of the experiment). The beetles were observed mating on the plants and puncturing plant tissues to drink the sap, but no eggs or larvae were observed. Given the frequency of sexual activity observed in the collection containers, all males were presumed to be sexually active and all females presumed to be mated. A subsample of 102 beetles were dissected immediately under a binocular microscope with $10 \times$ objective to verify the initial reproductive status of females and provide an estimate of population sex ratio. The remaining 242 insects were isolated individually in plastic Petri dishes (5.5 $\mathrm{cm}$ diameter) and divided up into four treatments: (1) an ad libitum diet of greenbug, $S$. graminum, reared on seedling sorghum plants grown in metal trays in a greenhouse and provided fresh daily, (2) an ad libitum diet of frozen eggs of the flour moth, Ephestia kuehniella provided fresh daily with water on a small cube of sponge, (3) excised petioles of wild sunflower replaced every second day and, (4) water alone provided fresh daily on a sponge cube.

The insects were held in a growth chamber at $24 \pm 2{ }^{\circ} \mathrm{C}$ under Phillips "coolwhite" fluorescent lighting set to a day length of 16L : 8D. All replicates were examined daily and any dead insects dissected to determine sex and presence/absence of vitellogenesis and/or fat bodies. Once mortality reached $50 \%$ in treatments (3) and (4), the remaining insects were switched to a diet of greenbug. Once a female began to reproduce, two of her egg clutches (= two days of reproduction) were collected and held in the same growth chamber as the adults until eclosion (4-5 days) to verify fertility. Treatment one was terminated on day 12 of the experiment, and all other treatments on day 38 .

We used a one-way ANOVA (SPSS, 1998) to compare the longevity of males and females that died in treatments 3 and 4 during the first 12 days of the experiment. A two-way ANOVA was then used to test for interaction between treatment and gender.

\section{RESULTS}

The sex ratio of the population was estimated to be $55 \%$ female from the initial sub sample of 102 beetles, 


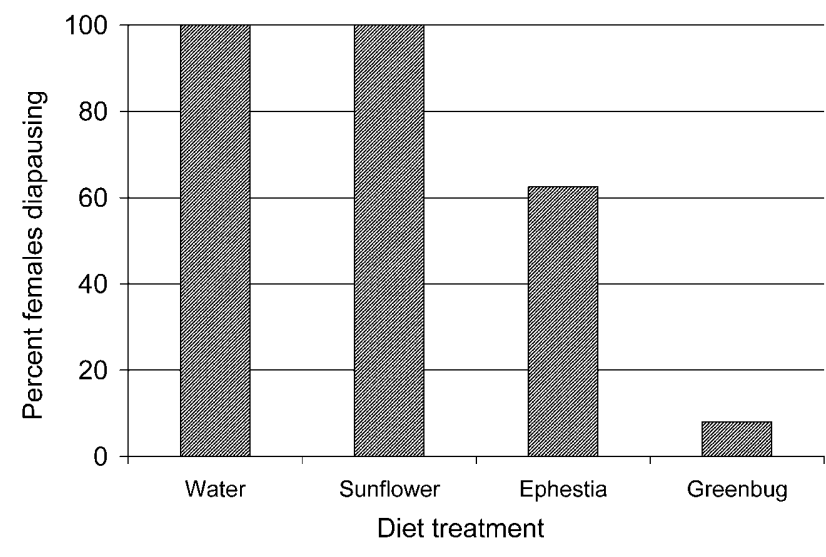

Fig. 4. Percentage of field-collected adult female Hippodamia convergens entering reproductive diapause when fed one of four diets in the laboratory: (1) water only, (2) excised petioles of wild sunflower, Helianthus annuus, (3) frozen eggs of the flour moth, Ephestia kuehniella, or (4) live greenbugs, Schizaphis graminum.

and $47 \%$ female from the total 338 beetles dissected in the experiment. None of the females dissected initially possessed mature eggs or had any evidence of vitellogenesis in their ovaries. We therefore concluded that these beetles represented first generation adults of 2004 that had not yet become reproductive. Of the remaining 242 beetles placed in experimental treatments, a total of six $(2.5 \%)$ turned out to be parasitized by Dinocampus (= Perilitus) coccinellae (Hymenoptera: Braconidae) and were excluded from all treatment comparisons. The percentage of females entering diapause in each of the four diet treatments is depicted in Fig. 4.

Of 41 beetles placed on a greenbug diet, 25 turned out to be females and, of these, $21(84 \%)$ began oviposition in a mean $( \pm \mathrm{SEM})$ of $6.0( \pm 0.5)$ days with high fertility $(89.7 \pm 3.8 \%$ of eggs hatching). Upon dissection of the remaining 20 beetles in this treatment on 6 June, we discovered two of the four females had fully mature eggs in their ovaries, suggesting they were about to begin oviposition, and the other two had fat bodies in the haemolymph, but no evidence of vitellogenesis. There was no mortality in this treatment during the 12 days the insects were observed.

Of the 40 beetles fed frozen eggs of E. kuehniella, 16 turned out to be females, 20, males, and 4 were parasitized. One female died on day 18 of the experiment, and three males died after 5, 6, and 21 days, respectively. Six of the females $(37.5 \%)$ began oviposition in a mean ( \pm SEM) of $19.7( \pm 3.5)$ days. One female had low fertility with only $6.7 \%$ of her eggs hatching, whereas the other five had high fertility, with 85.3 ( \pm 6.3$) \%$ of eggs hatching. After 38 days, only one of the nine remaining nonreproductive females had evidence of vitellogenesis, but all nine had produced fat bodies in the haemolymph.

We placed a total of 78 beetles into the sunflower petiole treatment, almost twice as many as in each of the protein diet treatments, as we intended to track mortality in this treatment until it reached $50 \%$ and then switch the survivors to a greenbug diet to observe their reproductive

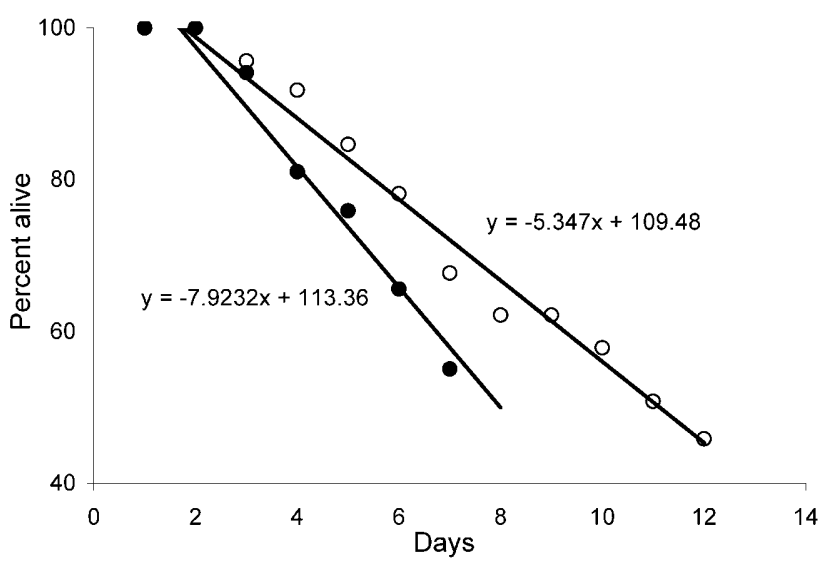

Fig. 5. Cumulative survival (in percent) of field-collected adult Hippodamia convergens isolated in plastic Petri dishes and held in a growth chamber at $24^{\circ} \mathrm{C}, 16: 8$ day length with access only to water (solid circles) or excised petioles of sunflower, Helianthus annuus (open circles). Treatments were terminated when $50 \%$ of beetles in a treatment were dead, at 7 days and 12 days, respectively.

responses. Of these beetles, 31 turned out to be females, 45 , males, and 2 were parasitized. On day 12 of the experiment, 15 females (48.4\%) and 27 males $(60.0 \%)$ had died, whereupon all survivors were provisioned with greenbugs. A total of seven females (43.8\% of survivors) began oviposition a mean $( \pm \mathrm{SEM})$ of 9.3 ( \pm 2.2$)$ days after the change in diet. One female produced only infertile eggs, whereas the other six had high fertility with a mean ( \pm SEM) of $89.8( \pm 3.8) \%$ of eggs hatching. Four additional males died after the change in diet (two the following day), but there was no further female mortality. When the experiment was terminated on day 38 , only one of the remaining nine females showed evidence of vitellogenesis upon dissection, whereas all females and males had fat bodies evident in their haemolymph.

We placed a total of 83 beetles into the "water only" treatment, 31 of which turned out to be females and 52, males. Once again, a larger number of beetles was used than in treatments with food available so that mortality could be tracked up to $50 \%$ before the survivors were switched to a greenbug diet. On day seven, a total of 13 females $(42 \%)$ and 26 males $(50 \%)$ had died and the remainder were provisioned with greenbugs. This mortality rate was marginally higher than for beetles receiving sunflower petioles (Fig. 5), such that 50\% mortality occurred five days earlier. A total of nine females ( $50 \%$ of survivors) began oviposition a mean $( \pm$ SEM) of $5.9 \pm 0.5$ days after the change in diet. One female produced only infertile eggs, but the other eight had good fertility with a mean $( \pm$ SEM) of $88.4( \pm 3.3) \%$ of eggs hatching. Five additional males died following the diet change, and two additional females. Of the six surviving females dissected on day 38, three had fat bodies in their haemolymph, but none had evidence of vitellogenesis.

The one-way ANOVA revealed that, of beetles failing to survive the first 12 days, both males and females in the sunflower petiole treatment lived significantly longer than 
did their counterparts in the water only treatment (males: $F=12.537 ; \mathrm{df}=1,51 ; P=0.001$; females: $F=4.670, \mathrm{df}$ $=1,27 ; P=0.040)$. Gender did not significantly affect longevity $(F=0.420 ; \mathrm{df}=1,78 ; P=0.519)$ and there was no significant interaction between treatment and gender $(F=0.042 ; \mathrm{df}=1,78 ; P=0.838)$.

\section{DISCUSSION}

Both of the "virtual starvation" treatments (water only and sunflower petioles) caused a majority of $H$. convergens females to enter a reproductive diapause, a state associated with arrested ovarian development and the accumulation of fat bodies. Immediate access to an abundant supply of greenbugs, a preferred and highly suitable prey for $H$. convergens, was sufficient to prevent a majority of first generation females $(92 \%)$ from entering reproductive diapause. These results indicate that few females had entered reproductive diapause at the time of collection, and that diapause was induced by food deprivation. All treatments were held under identical warm, long day length conditions that were reasonably representative of local summer field conditions, albeit without the extremes of temperature. Thus, if any environmental stimuli other than food had "primed" beetles for reproductive diapause, these were clearly not sufficient to induce diapause when suitable food was available.

The Ephestia egg treatment represented an inferior diet for this species relative to greenbugs and was less effective in averting diapause induction. Interestingly, this food supports completed larval development in $H$. convergens, but does not support reproduction unless the adult female has previously consumed more suitable aphid prey as either larva or adult (J.P. Michaud, unpubl. data). Less than half of the females on this diet matured eggs during the experimental period and they required, on average, more than three times as long to do so as the females fed on greenbugs. Thus, an abundance of suboptimal food may avert reproductive diapause in some females, but only a high quality diet will prevent diapause in a large proportion of females. Similarly, Iperti \& Hodek (1974) found they could induce and maintain diapause in Semiadalia undecimnotata Schn. adults by feeding them on a mixture of agar and honey after two days on an aphid diet.

Michaud \& Grant (2005) demonstrated that water availability can interact with non-aphid diets to affect larval survival, developmental rate and adult size in $C$. maculata, suggesting hydration can influence not only survival in the absence of food, but also the efficiency of food utilization. We did not include a "no water" treatment in these experiments on the assumption that desiccation would only accelerate mortality under conditions of high temperature and food deprivation, whether the insects diapaused or not. The observed LT 50's for beetles on water and sunflower petioles suggest that, reproductive diapause or no, first generation $H$. convergens evidently have only a week or two after emergence from pupae to find some form of supplementary food, even when hydration is adequate. Once entered, reproductive diapause proved to be a physiological state under relatively strong homeostatic control in the adult female. Thus, fully $50-60 \%$ of surviving females in the sunflower petiole and water only treatments failed to break their diapause even after being provided with a surfeit of greenbugs for 26 and 31 days, respectively.

The marginally higher rate of mortality in the wateronly treatment compared to the sunflower petiole treatment suggests that sunflower plants represent a valuable resource for first generation $H$. convergens adults, providing not only hydration, but also possibly some additional nutritional benefits. This is the first report, to our knowledge, that an aphidophagous coccinellid can receive supplementary nutrition directly from plant sap. Since we routinely observe many other coccinellid species drinking sunflower sap (C. maculata, C. septempunctata, Cycloneda munda (Say), Harmonia axyridis Pallas, and Scymnus spp.) the significance of this behavior warrants investigation on a broader scale. In addition, other aphid predators such as adult lacewings (Neuroptera: Chrysopidae), various parasitoid wasps, and a range of predatory Diptera and Hymenoptera can all be readily observed "drinking" from sunflowers on the High Plains.

Considerable sexual activity was observed among beetles at the time of their collection, although neither mature oocytes nor fat bodies were yet evident. As noted by Hodek \& Honěk (1996), sexual receptivity in female coccinellids is not known to depend on the state of their ovaries. Furthermore, most males dissected from all treatments at the end of the experiment had developed substantial fat bodies in their haemolymph very similar to those observed in non-reproductive females. Apparently, males also stored nutritional resources to prolong their survival under summer conditions. Follicular activity in the testes of male coccinellids is not known to be affected by diapause (Hodek \& Honěk, 1996). Nevertheless, one might expect the energy demands of fat body formation to lead to a scaled reduction of spermatogenesis in diapausing males, even if complete cessation does not occur. Unless male diapause is non-adaptive, diapausing males may gain incremental fitness by re-mating females that emerge from diapause, an inference consistent with a "last in - first out" rule of sperm precedence (Thornhill \& Alcock, 2001).

Assuming a generation time ranging from 35-40 days, $H$. convergens has the potential for two, or possibly three, generations per year in the High Plains, but only under conditions that render suitable prey continuously available. Populations of $C$. septempunctata show geographic variation across Europe in both voltinism and in the nature of diapause induction, but the availability of essential prey does not prevent diapause in all individuals (Hodek \& Honěk, 1996). Rather, diapause can be induced by substitution of essential prey with carbohydrate foods and environmental cues such as changes in temperature and photoperiod also appear to be involved (Hodek, 1962). Nechols et al. (1999) have argued that there is little value to distinguishing "facultative" from "obligatory" diapause because both are cued by environmental 
stimuli, the latter simply applying to cases in which the stimuli remain unidentified. However, the use of food quality or quantity as cues for diapause induction is very unlike the use of a simple, discrete environmental signal like photoperiod, since food directly affects many different aspects of beetle physiology, including the pool of resources available for development, body maintenance, and reproduction. Thus, the adaptive value of summer diapause to $H$. convergens life history may be maximized by its very mode of induction. Individuals can conserve energy and reproductive effort during periods when prey availability is inadequate to support the development of progeny, but can also avoid diapause in opportune situations where suitable prey remain continuously available throughout summer months.

Similar to $C$. septempunctata, $H$. convergens also has variable voltinism across its geographic range and other published evidence (summarized in Hagen, 1962) suggests that the actual number of generations is often dependent on prey availability. Hagen (1962) noted that $H$. convergens normally had only one generation per year in California, but had additional "atypical" summer generations when prey such as pea aphids, Acyrthosiphon pisum Harris, persisted into May. Furthermore, the invasion of California by the spotted alfalfa aphid, Therioaphis maculata (Buckton), was initially characterized by large, persistent aphid populations that caused $H$. convergens to maintain a year-round presence in alfalfa fields (Dickson et al., 1955; van den Bosch et al., 1959). Although the results of the present study confirm that food availability and quality are primary determinants of summer diapause induction in $H$. convergens populations on the High Plains, the stimuli cueing diapause termination remain unknown. Obrycki \& Tauber (1979) showed that winter diapause in $C$. maculata is maintained by short photoperiod, but its termination in spring is accelerated by warm temperatures and the presence of suitable prey. Diapause is rarely a uniform phenomenon among all individuals in a population and there was considerable variation among individual females in their responses within each of our experimental treatments. As pointed out by Hodek (1983) few studies have addressed the environmental factors regulating reproduction after diapause. Do factors such as temperature cycles and/or photoperiod influence the proportion of $H$. convergens females predisposed to enter, or break, diapause at particular times of year? Can beetles that enter reproductive diapause in June also hibernate to reproduce the following spring, or is an interim fall generation required to produce beetles capable of successful hibernation? Answers to these questions are needed to further clarify the seasonal life history of $H$. convergens in the High Plains.

ACKNOWLEDGEMENTS. We are thankful to J. Leiker for assisting with the rearing of greenbugs for these experiments, and to J. Nechols, I. Hodek and one anonymous reviewer for constructive criticism of the manuscript. USDA-APHIS provided financial support for JAQ. Contribution No. 05-268-J from the Kansas Agricultural Experiment Station.

\section{REFERENCES}

BRASSLER K. 1930: Ist Coccinella septempunctata wirklich nur Blattlausfresser? Z. PflKrankh. PflPath. PflShutz 40: 511-513.

Cloyd R.A. 2004: Asian lady beetle, Harmonia axyridis. University of Illinois Extension Service Bulletin. Available online: http://www.ipm.uiuc.edu/hyg/insects/asian_lady_beetle/.

Dickson R.C., Laird E.F. JR. \& Pesho G.R. 1955: The spotted alfalfa aphid (yellow clover aphid on alfalfa). Hilgardia 24: 93-118.

HaGEN K.S. 1962: Biology and ecology of predaceous Coccinellidae. Annu. Rev. Entomol. 7: 289-326.

HoDEK I. 1962: Experimental influencing of the imaginal diapause in Coccinella septempunctata L. (Coleoptera: Coccinellidae). Čas. Čs. Spol. Entomol. 59: 297-313.

HoDEK I. 1983: Role of environmental factors and endogenous mechanisms in the seasonality of reproduction in insects diapausing as adults. In Hodek I. \& Brown V.K. (eds): Diapause and Life Cycle Strategies in Insects. Junk, The Hague, pp. 22-33.

HodeK I. \& HonĚK A. 1996: Ecology of Coccinellidae. Kluwer Academic, Dordrecht, 464 pp.

IPERTI G. \& HoDeK I. 1974: Induction alimentaire de la dormance imaginale chez Semidalia undecimnotata Schn. (Coleoptera: Coccinellidae) pour aider à la conservation des coccinelles elevées au laboratoire avant une utilisation ultérieure. Ann. Zool. Ecol. Anim. 6: 41-51.

Koch R.L. 2003: The multicolored Asian lady beetle, Harmonia axyridis: A review of its biology, uses in biological control, and non-target impacts. J. Ins. Sci. 3: 32, Available online: insectscience.org/3.32.

Masaki S. 1980: Summer diapause. Annu. Rev. Entomol. 25: $1-25$.

Michaud J.P. \& GRANT A.K. 2005: Suitability of pollen sources for development and reproduction of Coleomegilla maculata (Coleoptera: Coccinellidae) under simulated drought conditions. Biol. Contr. 32: 363-370.

Nechols J.R., Tauber M.J., Tauber C.A. \& Masaki S. 1999: Adaptations to hazardous seasonal conditions: Dormancy, migration and polyphenism. In Huffaker C.B. \& Gutierrez A.P. (eds): Ecological Entomology. 2nd ed. Wiley, New York, pp. 159-200.

Obrycki J.J. \& TAuber M.J. 1979: Seasonal synchrony of the parasite Perilitus coccinellae and its host Coleomegilla maculata. Environ. Entomol. 8: 400-405.

Royer T.A. \& WALgEnBACH D.D. 1991: Predaceous arthropods of cultivated sunflower in eastern North Dakota. J. Kans. Entomol. Soc. 64: 112-116.

SPSS 1998: SPSS 8.0 for windows. SPSS Inc., Prentice Hall, New Jersey.

Thornhill R. \& Alcock J. 2001: The Evolution of Insect Mating Systems. Universe.com, Lincoln, Nebraska, 547 pp.

Turnock W.J. \& Turnock R.W. 1979: Aggregations of lady beetles (Coleoptera: Coccinellidae) on the shores of Lake Manitoba. Man. Entomol. 13: 21-22.

Van den Bosch R., Schlinger E.I., Dietrick E.J. \& Hall I. 1959: The role of imported parasites in the biological control of the spotted alfalfa aphid in southern California. J. Econ. Entomol. 52: 142-154.

Received February 2, 2005; revised and accepted April 15, 2005 